\title{
Characteristics of a Reclaimed Tidal Soil for Effective Resalization at Saemangum and Youngsan-River
}

\author{
Doug-Young Chung, Hyejin Kim, Misuk Park, and Sang-Eun Lee ${ }^{1 *}$ \\ Dept. of Bio-environmental Chemistry, College of Agriculture and Life Sciences, \\ Chungnam National University, Daejeon 305-764, Korea \\ ${ }^{1}$ Dept. of Plant Resources Sciences, Hankyung National University, Ansung 456-749, Korea
}

\begin{abstract}
The total area of a reclaimed tidal soil distributed on the south-west coast is approximately $156,600 \mathrm{ha}$, and the soil contains high contents of sand and silt as well as highly saline. Most of the reclaimed tidal soils are used as a paddy due to bad permeability and high groundwater table, resulting in easy accumulation of salts on the soil surface by capillary rise. Therefore, resalinization may occur because of rise of groundwater table after desalinization. The researches related to the reclaimed tidal soil mainly focused on desalinazation while most of the researches completed were limited to yields of crop based on desalinazation. $\mathrm{pH}$ of old reclaimed tidal soil is neutral or less than 7 while that of newly developed reclaimed tidal soils is greater than 7 , that cause $\mathrm{N}$-fertilizer to be volatile as ammonia. Thus, the physical and chemical properties should be investigated to be used as an arable upland instead of a paddy soil due to change in government policy. We need to develop measures to make soils grow crops normally by identifying problems related to reclaimed tidal soils.
\end{abstract}

Key words: Reclaimed Tidal Soil, Resalization, Saline

\section{서 언}

우리나라의 식량자급률은 50\% 내외로 낮고 곡물자급률 은 사료부문을 포함하여도 $26 \%$ 로 매우 낮은 수준이나 우리 나라의 농경지는 산업화에 따른 타용도 전용 등으로 ' 98 년 이후 매년 평균 15 천ha씩 급속히 감소되고 있는 추세에 있 다 (2009 Yearbook of MAF). 따라서 식량의 안정적 공급을 위한 기본적인 농경지의 확보가 필요하며 이러한 상황에서 간척지는 식량의 안정적 공급을 위한 경지면적을 확보한다 는 면에 있어 그 의의가 크다.

우리나라의 서남해안은 내부 간석지의 면적이 넓어 짧은 방조제를 축조하여 넓은 땅을 개발할 수 있다. 우리나라의 서남해안 총 간척자원은 81만ha로 이중 개발가능 면적은 51 만 9천ha이고 $(1995, \mathrm{KRCC})$, 간척사업 추진현황을 살펴보 면 총 대상면적이 $156,603 \mathrm{ha}$ 중 준공한 면적은 약 97,000 ha이다. 한편 연도별 개발현황을 살펴보면 1945년 이전 총 개발면적은 약 40,877 ha이며 1946년 이후 총 1628 개소에 서 간척지 개발이 실시되었다. 이중 정부가 시행한 지구 수 는 186 개소 약 $3558 \mathrm{ha}$ 이고 민간주도로 약 1442 개소 총면적 약 40200ha 정도가 개발된 되었다 (KRCC, 2002; NHAES, 2002).

현재 국내 간척지는 염농도가 높고 모래와 미사가 많고 지하수위가 높아 배수가 불량하고 표토에 염분집적이 쉬울

\footnotetext{
접수 : 2012. 11. 16 수리 : 2012. 11. 30

*연락저자 : Phone: +821047855085

E-mail: selee@hknu,ac.kr
}

뿐만 아니라 제염을 실시한 후 다시 지하수 상승 등에 의한 재염화가 발생하고 있다 (Ryu, 2009).

국립식량과학원 간척지농업과에서 남양간척지에 대해 조 사한 바에 따르면 초기 염농도가 약 $1.6 \%$ (약 $25 \mathrm{dS} \mathrm{m}^{-1}$ )인 미사질양토 (표토)와 미사질식양토(심토)를 자연강우를 이 용하여 벼재배임계농도인 염농도 $0.3 \%$ (약 $4.7 \mathrm{dS} \mathrm{m}^{-1}$ )로 낮추는데 소요된 제염시간을 살펴보면 표토 $(0 \sim 10 \mathrm{~cm})$ 의 경우는 약 40년 그리고 심토 $(60 \sim 120 \mathrm{~cm})$ 는 약 90년이 소 요된다. 한편 계화도 포승통의 경우 영농 후 약 50 년의 시 간이 지났음에도 불구하고 벼재배임계농도인 염농도 $0.3 \%$ (약 $4.7 \mathrm{dS} \mathrm{m}^{-1}$ ) 보다 높은 $0.44 \%$ 정도로 조사되었으며 광 활과 문포통의 경우 영농 후 20 년 정도 시간이 지난 후부터 벼재배임계농도인 염농도 $0.3 \%$ 이하로 감소되는 것으로 보 고되었다. 따라서 계화도 간척지의 경우 세사양토 사양토 의 경우 약 20 년, 그리고 미사질양토의 경우 33 년 내지 약 50 년 정도 소요되는 것으로 추정된다. 그러므로 간척지를 효율적으로 활용하기 위한 간척지 토양의 조기 숙전화기술 이 개발되어야 한다.

국내 간척지 토양의 이화학 특성 우리나라의 간척지 토양통은 모두 47 개로 논토양 5 개 유형, 밭토양 2 개 유형으 로 분류하며 47 개 토양통 중 논토양은 40 개로 보통답 15 개, 사질답 6 개, 습답 8 개, 염해답 8개, 특이산성답 3 개 토양통 으로 구분되고, 밭토양은 7 개 토양통으로 보통전 1 개, 사질 전 6개 토양통으로 구분한다 (Ryu, 2008). 1920년도에 완성 

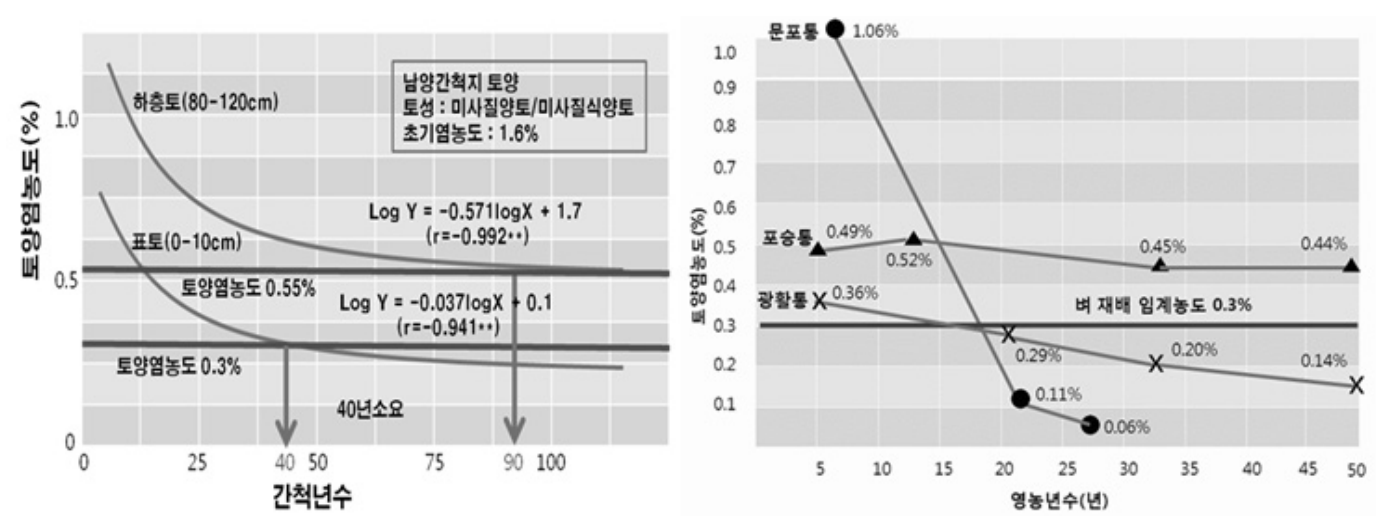

Fig. 1. Change in salt concentration based on cultivated period at Poseung series in Gyehwa island (right) and desalinization period for each soil layer at Namyang reclaimed tidal land under natural precipitation (left).

Table 1. General information of the reclaimed tidal land developed since 1920.

\begin{tabular}{|c|c|c|c|c|c|c|c|c|c|}
\hline \multirow{2}{*}{$\begin{array}{c}\text { Year of } \\
\text { completion }\end{array}$} & \multirow{2}{*}{ Location } & \multirow{2}{*}{$\begin{array}{c}\text { Soil } \\
\text { series }\end{array}$} & \multirow{2}{*}{ Layer } & \multirow{2}{*}{ Depth } & \multicolumn{3}{|c|}{ Soil particle distribution } & \multirow{2}{*}{$\begin{array}{c}\text { Soil } \\
\text { texture }\end{array}$} & \multirow{2}{*}{$\begin{array}{c}\text { Ground- } \\
\text { water table }\end{array}$} \\
\hline & & & & & Sand & Silt & Clay & & \\
\hline \multirow{5}{*}{-} & \multirow{5}{*}{ Osan } & \multirow{5}{*}{ Junbook } & & $\mathrm{cm}$ & & & & & $\mathrm{cm}$ \\
\hline & & & A & $0-18$ & 5 & 77 & 18 & $\mathrm{SiL}$ & \multirow{4}{*}{$<100$} \\
\hline & & & B1 & $18-25$ & 8 & 71 & 21 & $\mathrm{SiL}$ & \\
\hline & & & B2 & $25-75$ & 29 & 56 & 15 & $\mathrm{SiL}$ & \\
\hline & & & $\mathrm{C}$ & $75-$ & 40 & 53 & 7 & $\mathrm{SiL}$ & \\
\hline \multirow{6}{*}{1920} & \multirow{4}{*}{ Hwapo } & \multirow{4}{*}{ Buyong } & $\mathrm{A}$ & $0-21$ & 3 & 69 & 28 & $\mathrm{SiCL}$ & \multirow{4}{*}{70} \\
\hline & & & B & $21-26$ & 3 & 59 & 38 & $\mathrm{SiCL}$ & \\
\hline & & & $\mathrm{C} 1$ & $26-70$ & 7 & 61 & 32 & $\mathrm{SiCL}$ & \\
\hline & & & $\mathrm{C} 2$ & $70-$ & 4 & 58 & 38 & $\mathrm{SiCL}$ & \\
\hline & \multirow{2}{*}{$\begin{array}{c}\text { Jinbong, Gwanghal, } \\
\text { Daehang, Seopo }\end{array}$} & \multirow{2}{*}{ Mangyung } & A & $0-20$ & 18 & 50 & 17 & $\mathrm{SiL}$ & \multirow{2}{*}{90} \\
\hline & & & $\mathrm{C}$ & $20-$ & 14 & 70 & 16 & $\mathrm{SiL}$ & \\
\hline \multirow{3}{*}{1930} & \multirow{3}{*}{$\begin{array}{c}\text { Daeya } \\
\text { Howhyun }\end{array}$} & \multirow{3}{*}{ Mangyung } & A & $0-23$ & 19 & 67 & 14 & $\mathrm{SiL}$ & \multirow{3}{*}{73} \\
\hline & & & $\mathrm{C} 1$ & $23-60$ & 36 & 59 & 5 & $\mathrm{SiL}$ & \\
\hline & & & $\mathrm{C} 2$ & $60-$ & 41 & 55 & 5 & $\mathrm{SiL}$ & \\
\hline \multirow{2}{*}{1960} & \multirow{2}{*}{ Mimyon } & \multirow{2}{*}{ Mangyung } & A & $0-18$ & 29 & 58 & 13 & $\mathrm{SiL}$ & \multirow{2}{*}{$<100$} \\
\hline & & & $\mathrm{C}$ & $18-$ & 34 & 63 & 3 & $\mathrm{SiL}$ & \\
\hline \multirow{3}{*}{1970} & \multirow{3}{*}{$\begin{array}{l}\text { Oksuh } \\
\text { Gyehwa }\end{array}$} & \multirow{3}{*}{$\begin{array}{l}\text { Mangyung } \\
\text { Moonpo }\end{array}$} & A & $0-23$ & 42 & 53 & 5 & $\mathrm{SiL}$ & \multirow{3}{*}{65} \\
\hline & & & $\mathrm{C} 1$ & $23-64$ & 57 & 39 & 4 & SL & \\
\hline & & & $\mathrm{C} 2$ & $64-$ & 76 & 21 & 3 & LS & \\
\hline \multirow{2}{*}{1980} & Imhae Industrial & Мапоудйо & A & $0-22$ & 35 & 53 & 12 & $\mathrm{SiL}$ & $<100$ \\
\hline & site & Mangyung & $\mathrm{C}$ & $22-$ & 40 & 47 & 13 & SL & \\
\hline 2000 & $\begin{array}{c}\text { Gunsan, Gwanghal, } \\
\text { Gyehwa }\end{array}$ & $\begin{array}{c}\text { Mangyung } \\
\text { Moonpo Yumpo }\end{array}$ & A & $0-20$ & 44 & 47 & 9 & SL & - \\
\hline
\end{tabular}

한 화포와 진봉, 대창 등의 간척지로부터 최근 완성된 새만 금간척지의 토양통은 전북, 부용, 만경, 문포, 염포통이 주 를 이루며 $\mathrm{A}$ 층은 $25 \mathrm{~cm}$ 이내로 토성은 미사질양토, 미사질 식양토, 그리고 일부 지역은 사질양토로 조사되었다. 그리 고 지하수위 위치는 모두 지표면으로부터 $100 \mathrm{~cm}$ 이내에 존 재하는 것으로 조사되었다 (Table 1).
그리고 화학성을 비교하여 (Table 2) 보면 간척지 토양통 이 토양의 이화학성에 영향을 미치는 것으로 판단되며 1920 년 이전 개발 간척지는 토층분화가 생성된 반면 1930년대 이후 개발된 간척지는 대부분 표층에 해당하는 $\mathrm{A}$ 층 하부에 층이 존재하는 것으로 조사되었다 (NHAES, 2002). 
Table 2. Chemical properties of the reclaimed tidal soils developed since 1920.

\begin{tabular}{|c|c|c|c|c|c|c|c|c|c|c|c|c|c|c|}
\hline \multirow{2}{*}{$\begin{array}{c}\text { Year of } \\
\text { completion }\end{array}$} & \multirow{2}{*}{ Location } & \multirow{2}{*}{$\begin{array}{c}\text { Soil } \\
\text { series }\end{array}$} & \multirow{2}{*}{ Layer } & \multirow{2}{*}{ Depth } & \multirow[t]{2}{*}{$\mathrm{pH}$} & \multirow[t]{2}{*}{$\mathrm{EC}$} & \multirow[t]{2}{*}{$\mathrm{OM}$} & \multirow[t]{2}{*}{$\mathrm{TN}$} & \multirow[t]{2}{*}{ Av. $\mathrm{P}_{2} \mathrm{O}_{5}$} & \multicolumn{4}{|c|}{ Ex.cations } & \multirow{2}{*}{ CEC } \\
\hline & & & & & & & & & & $\mathrm{K}$ & $\mathrm{Ca}$ & $\mathrm{Mg}$ & $\mathrm{Na}$ & \\
\hline & & & & $\mathrm{cm}$ & $1: 5$ & $\mathrm{dS} \mathrm{m}^{-1}$ & $\mathrm{~g} \mathrm{k}$ & $g^{-1}$ & $\mathrm{mg} \mathrm{kg}^{-1}$ & - & $-\mathrm{cm}$ & $\mathrm{kg}^{-1}$ & - & \\
\hline \multirow{4}{*}{-} & \multirow{4}{*}{ Osan } & \multirow{4}{*}{ Junbook } & A & $0-18$ & 5.9 & 0.5 & 15.2 & 1.20 & 186 & 0.50 & 6.6 & 3.3 & 0.4 & 14.0 \\
\hline & & & B1 & $18-25$ & 6.5 & 0.3 & 14.5 & 1.00 & 142 & 0.60 & 6.5 & 3.9 & 0.4 & 15.5 \\
\hline & & & B2 & $25-75$ & 7.1 & 0.3 & 5.6 & 0.20 & 21 & 0.50 & 4.8 & 4.1 & 0.4 & 13.7 \\
\hline & & & $\mathrm{C}$ & $75-$ & 7.1 & 0.2 & 2.5 & 0.10 & 41 & 0.50 & 3.0 & 4.3 & 0.3 & 9.2 \\
\hline \multirow{6}{*}{1920} & \multirow{4}{*}{ Hwapo } & \multirow{4}{*}{ Buyong } & A & $0-21$ & 5.5 & 0.7 & 16.1 & 1.14 & 112 & 0.28 & 4.2 & 2.5 & 0.7 & 10.8 \\
\hline & & & B & $21-26$ & 7.6 & 0.8 & 6.8 & 0.13 & 1 & 0.65 & 4.8 & 5.1 & 1.5 & 11.9 \\
\hline & & & $\mathrm{C} 1$ & $26-70$ & 7.7 & 0.9 & 4.3 & 0.16 & 5 & 0.90 & 5.2 & 9.0 & 3.1 & 17.5 \\
\hline & & & $\mathrm{C} 2$ & $70-$ & 7.8 & 1.0 & 4.1 & 0.21 & 10 & 0.90 & 4.7 & 8.7 & 3.4 & 18.2 \\
\hline & \multirow{2}{*}{$\begin{array}{c}\text { Jinbong, } \\
\text { Gwanghal, } \\
\text { Daehang, } \\
\text { Seopo }\end{array}$} & \multirow[b]{2}{*}{ Mangyung } & A & $0-20$ & 5.9 & 0.7 & 14.9 & 1.15 & 168 & 0.14 & 5.2 & 2.4 & 0.5 & 9.9 \\
\hline & & & $\mathrm{C}$ & $20-$ & 7.5 & 0.5 & 2.6 & 0.16 & 8 & 0.29 & 4.4 & 4.7 & 1.1 & 10.3 \\
\hline \multirow{3}{*}{1930} & \multirow{3}{*}{$\begin{array}{c}\text { Daeya } \\
\text { Howhyun }\end{array}$} & \multirow{3}{*}{ Mangyung } & A & $0-23$ & 6.6 & 0.8 & 14.9 & 1.12 & 141 & 0.26 & 6.1 & 2.5 & 0.5 & 9.4 \\
\hline & & & $\mathrm{C} 1$ & $23-60$ & 7.7 & 0.5 & 2.9 & 0.16 & 5 & 0.49 & 4.7 & 5.8 & 0.8 & 11.2 \\
\hline & & & $\mathrm{C} 2$ & $60-$ & 7.8 & 0.5 & 2.0 & 0.15 & 13 & 0.65 & 3.5 & 5.8 & 1.3 & 10.3 \\
\hline \multirow{2}{*}{1960} & \multirow{2}{*}{ Mimyon } & \multirow{2}{*}{ Mangyung } & A & $0-18$ & 6.2 & 1.6 & 15.0 & 0.90 & 243 & 0.40 & 4.3 & 3.3 & 1.2 & 9.0 \\
\hline & & & $\mathrm{C}$ & $18-$ & 7.9 & 1.0 & 1.1 & 0.10 & 17 & 0.50 & 2.2 & 3.6 & 1.0 & 5.6 \\
\hline \multirow{3}{*}{1970} & \multirow{3}{*}{$\begin{array}{c}\text { Oksuh } \\
\text { Gyehwa }\end{array}$} & \multirow{3}{*}{$\begin{array}{c}\text { Mangyung } \\
\text { Moonpo }\end{array}$} & A & $0-23$ & 6.3 & 3.6 & 14.3 & 0.96 & 108 & 0.46 & 5.3 & 4.2 & 3.2 & 9.9 \\
\hline & & & $\mathrm{C} 1$ & $23-64$ & 8.3 & 2.4 & 2.8 & 0.11 & 22 & 0.70 & 2.6 & 3.8 & 3.1 & 7.4 \\
\hline & & & $\mathrm{C} 2$ & $64-$ & 8.3 & 3.5 & 2.3 & 0.15 & 23 & 0.85 & 1.8 & 4.1 & 4.9 & 8.0 \\
\hline \multirow{2}{*}{1980} & Imhae & Мапоурипо & A & $0-22$ & 6.4 & 1.3 & 12.5 & 0.80 & 100 & 0.40 & 5.2 & 3.4 & 1.2 & 11.0 \\
\hline & Ind. site & N⿴囗апу уй & $\mathrm{C}$ & $22-$ & 8.4 & 0.9 & 3.7 & 0.10 & 22 & 1.10 & 3.0 & 4.8 & 1.9 & 9.9 \\
\hline 2000 & $\begin{array}{c}\text { Hwapo, } \\
\text { Gunsan, } \\
\text { Gwanghal, } \\
\text { Gyehwa }\end{array}$ & $\begin{array}{c}\text { Mangyung } \\
\text { Moonpo } \\
\text { Yumpo }\end{array}$ & A & $0-17$ & 8.3 & 3.2 & 3.3 & - & 28 & 1.10 & 2.6 & 5.5 & 12.5 & - \\
\hline
\end{tabular}

간척지 토양의 이화학 특성 새만금 간척지는 전북 옥 구군 옥서면을 중심으로 금강, 만경강, 동진강 하구 갯벌을 개발한 간척지로 새만금간척지내에 존재하는 토양통은 문 포, 염포, 광활, 포승, 만경통 총 5 개의 토양통이 카테나를 이루고 있다 (Ryu, 2008). 새만금지역의 A 또는 Ap층의 깊 이는 $20 \mathrm{~cm}$ 이내이며 대부분 하부에 $\mathrm{C}$ 층이 바로 연결돼 있 다 (Fig. 2).

Yang(2008)이 조사한 새만금 문포, 염포, 광활통의 년간 지하수위 변동 조사 결과를 살펴보면 문포통의 지하수위는 봄철에 가장 높고 여름보다 가을에 지하수위는 최저 약 71 $\mathrm{cm}$ 로 낮아지고 반면 염포와 광활통은 봄보다 가을철에 지 하수위가 낮아지며 반면 최대 지하수위는 여름에 $18 \mathrm{~cm}$ 와 $11 \mathrm{~cm}$ 로 지표면 가까이까지 상승되는 것으로 발표하였다. 그리고 Ryu(2008)가 조사한 토양통별 토양의 토성은 미사 질양토 미사질식양토로 배수등급은 약간 불량 불량 매 우 불량한 토양으로 벼 재배에는 큰 문제가 없으나 밭작물

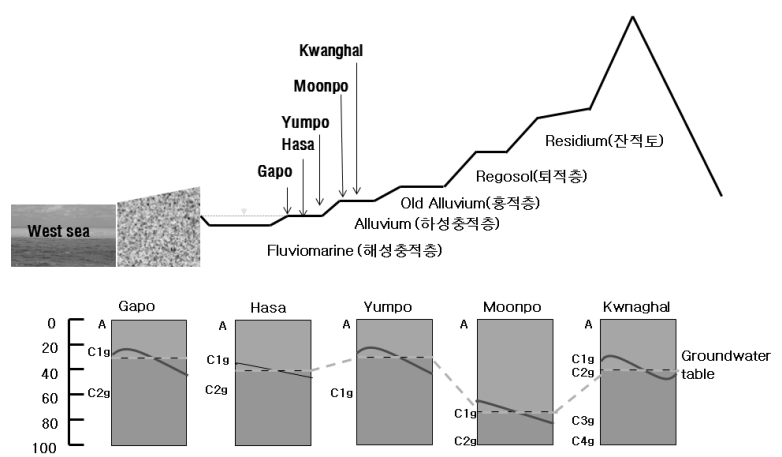

Fig. 2. Catena and ground-water levels of soil series at the Saemangum reclaimed tidal land area (Ryu, 2010).

재배에는 토양배수 등의 문제로 적합하지 못하다 (Ryu, 2008). 또한 지하수위에 따라 토양의 형태 및 토색이 상이 하며 지하수의 영향으로 기층은 심히 환원되어 토색이 청회 색 내지 암회색을 나타내고 액화상태이며 토양 중 반문은 
거의 형성되어 있지 않다. 작토 및 심토층은 각각 회갈색, 암회색을 나타내고, 농적갈색의 $\mathrm{Mn}$ 반문을 포함하는 무구 조이다 (Fig. 3).

한편 계절별 지하수위 지점에서의 염류농도를 살펴보면 (Table 3) 조사된 토양통 모두 여름에 가장 높고 봄과 가을 은 유사한 것으로 조사되었다 (Yang, 2008).

한편 한국농어촌공사가 2009년 개발한 영산강간척지 III 지 구 토양조사 결과를 살펴보면 총 5 개의 토양통으로 구성되어 있으며 (Fig. 4), 내륙에서부터 태안, 광포, 복천 (또는 전북), 그리고 포승통의 순서로 토양통이 배열돼 있다 (Lee, 2008).

그리고 각각의 토양통별 깊이에 따른 토성을 살펴보면 표층은 사질양토 $(\mathrm{SL})$ 또는 미사질식양토 $(\mathrm{SiCL})$ 가 혼재하 며 심층은 사질양토와 양토 $(\mathrm{SL} / \mathrm{L})$ 가 혼재하며 전북과 포승 통은 미사질양토와 미사질식양토 $(\mathrm{SiL} / \mathrm{SiC})$ 가 혼재하는 상 태로 조사되었다 (Table 3), 특히 내륙에 위치하는 태안통의
경우 기반층의 경우 모래 $(\mathrm{S})$ 와 함께 자갈이 함께 혼재하는 상태로 조사되었다. 배수특성은 소택지로 존재하는 포승과 복천통이 매우 불량 (Bad)한 것으로 조사되었다 (Jung, 2008; NHAES. 2002).

그리고 Fig. 5에서 보는 바와 같이 영산호 III 지구 간척 지 토양은 지하수위에 따라 기층은 심히 환원되어 토색이 청회색 내지 암회색을 나타내고 액화상태이며 토양 중 반문 은 거의 형성되지 않은 (non-mottle) 토양의 구조와 토색의 특성을 보이며 작토 및 심토층은 각각 회갈색, 암회색 을 나 타내고, 농적갈색의 $\mathrm{Mn}$-반문을 포함하며 무구조이다 (Lee, 2008). 이와 같이 토양의 형태적 특성에 큰 영향을 미치는 지하수위는 45 95 cm 범위로 포승통은 $50 \mathrm{~cm}$ 정도로 높 다 (Lee, 2008). 그리고 표토의 토성은 사양토 또는 미사질 양토로 조사되었으며 심층은 사양토, 미사질양토 또는 양토 로 조사되었다. 한편 기층은 자갈이 많은 사양토부터 심층
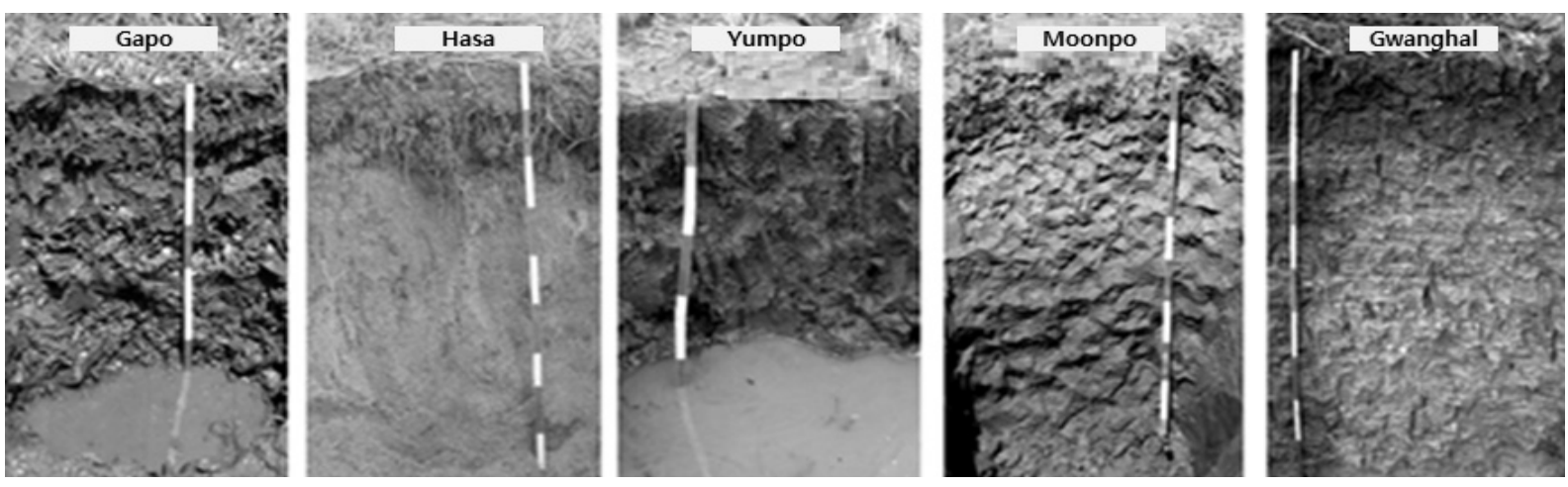

Fig. 3. Status of ground-water table and soil profiles for soil series at the Saemangum reclaimed tidal area (NHAES. 2002).

Table 3. Depth and salt content at the level of ground-water-water table measured at the soil series of Moonpo, Yumpo, and Kwanghal at Saemangum reclaimed tidal area.

\begin{tabular}{|c|c|c|c|c|c|c|}
\hline \multirow{2}{*}{$\begin{array}{c}\text { Soil } \\
\text { series }\end{array}$} & \multicolumn{3}{|c|}{ Ground-water table } & \multicolumn{3}{|c|}{ Salt content of Ground-water } \\
\hline & Spring & Summer & Fall & Spring & Summer & Fall \\
\hline & \multicolumn{3}{|c|}{ 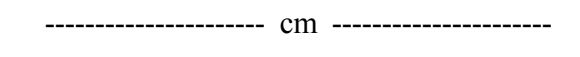 } & \multicolumn{3}{|c|}{ 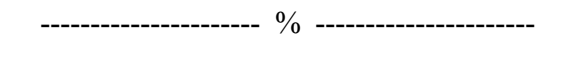 } \\
\hline Moonpo & 18 & 20 & 71 & 0.12 & 0.44 & 0.10 \\
\hline Yumpo & 37 & 18 & 60 & 0.07 & 0.39 & 0.08 \\
\hline Gwanghal & 31 & 11 & 33 & 0.38 & 0.70 & 0.25 \\
\hline
\end{tabular}
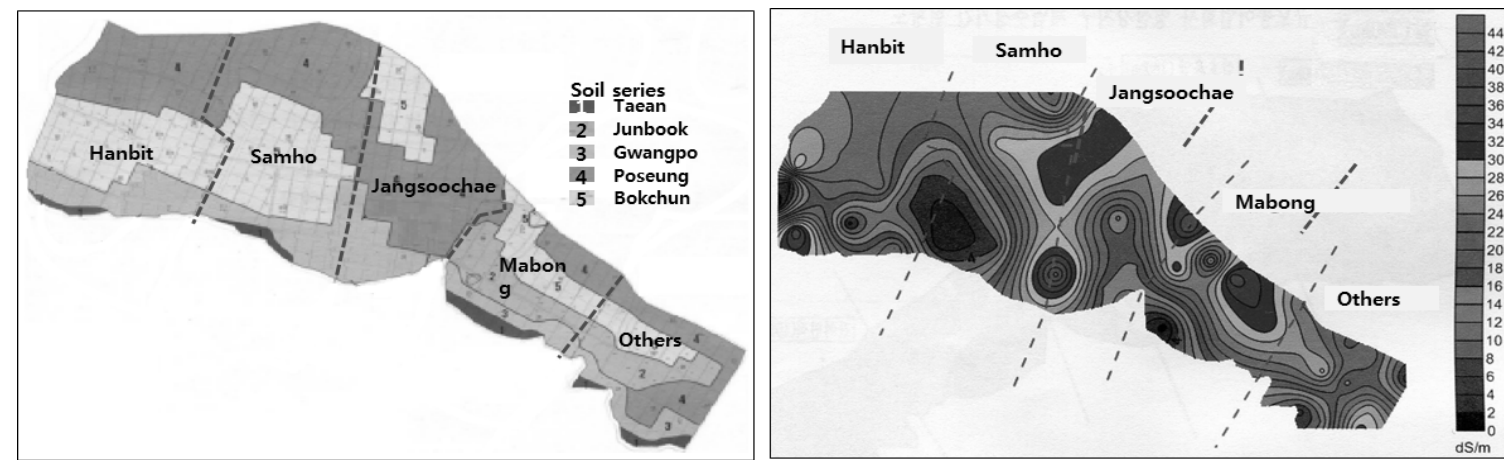

Fig. 4. Distribution of soil series (left) and salt contents of surface soils (right) at Youngsan-river reclaimed tidal area. 

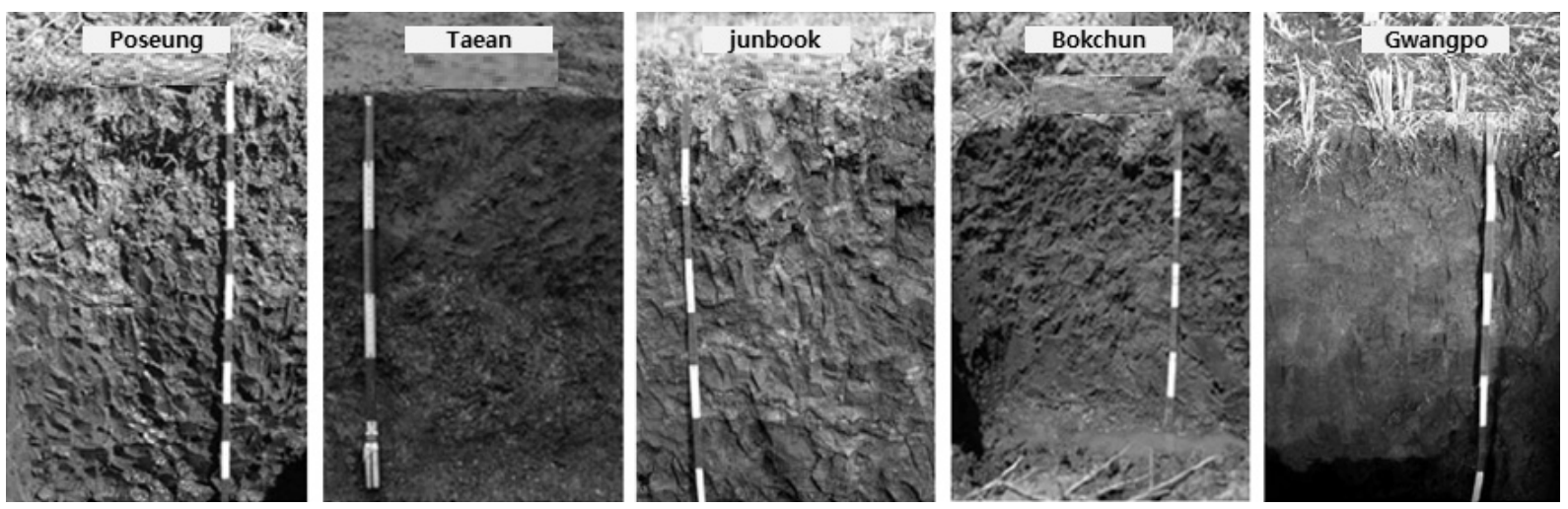

Fig. 5. Soil profiles of the soil series at the Youngsan-river reclaimed tidal soils.

Table 5. Chemical and physical properties of a reclaimed tidal soils in Saemangum area.

\begin{tabular}{|c|c|c|c|c|c|c|c|c|c|c|c|c|c|}
\hline \multirow{2}{*}{$\begin{array}{l}\text { Soil } \\
\text { series }\end{array}$} & \multirow[t]{2}{*}{ Horizon } & \multirow[t]{2}{*}{ Depth } & \multirow[t]{2}{*}{$\mathrm{pH}$} & \multirow[t]{2}{*}{$\mathrm{EC}$} & \multirow[t]{2}{*}{$\mathrm{OM}$} & \multicolumn{4}{|c|}{ Ex. cation } & \multicolumn{3}{|c|}{$\begin{array}{l}\text { Soil particle } \\
\text { distribution }\end{array}$} & \multirow{2}{*}{$\begin{array}{l}\text { Soil } \\
\text { texture }\end{array}$} \\
\hline & & & & & & $\mathrm{Ca}$ & $\mathrm{Mg}$ & $\mathrm{Na}$ & $\mathrm{K}$ & Sand & Silt & Clay & \\
\hline & & $\mathrm{cm}$ & $1: 5$ & $\mathrm{dS} \mathrm{m}^{-1}$ & $\%$ & - & $-\mathrm{cmo}$ & $\mathrm{kg}^{-1}$ & ---- & 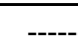 & $\%$ & ב--- & \\
\hline \multirow{2}{*}{ Hasa } & $\mathrm{AP}$ & $0 \sim 13$ & 6.8 & 4.69 & 0.24 & 1.2 & 0.45 & 1.4 & 0.08 & 94.8 & 1.8 & 3.4 & S \\
\hline & $\mathrm{C} 1$ & $13 \sim 21$ & 7.7 & 3.13 & 0.31 & 1.5 & 0.33 & 1.4 & 0.10 & 92.4 & 3 & 4.6 & S \\
\hline \multirow{2}{*}{ Yumpo } & AP & $0 \sim 10$ & 5.6 & 15.63 & 0.56 & 1.2 & 1.41 & 4 & 0.23 & 69.7 & 25.3 & 5 & SL \\
\hline & $\mathrm{Clg}$ & $10 \sim 55$ & 5.5 & 9.38 & 0.47 & 1.3 & 1.31 & 3.9 & 0.11 & 75.9 & 20.9 & 3.2 & LS \\
\hline \multirow{3}{*}{ Moonpo } & AP1 & $0 \sim 8$ & 6.7 & 9.38 & 0.80 & 1.5 & 3.6 & 2.4 & 0.26 & 47 & 46.5 & 6.5 & $\mathrm{~S}$ \\
\hline & AP2 & $8 \sim 18$ & 8.1 & 12.50 & 0.24 & 1.5 & 3.5 & 3.2 & 0.39 & 51.7 & 42 & 6.3 & S \\
\hline & $\mathrm{C} 1 \mathrm{~g}$ & $18 \sim 70$ & 8.1 & 20.31 & 0.19 & 1.6 & 2.8 & 3.6 & 0.50 & 87 & 10.5 & 2.5 & S \\
\hline \multirow{3}{*}{ Gwanghal } & AP1g & $0 \sim 12$ & 7.4 & 10.94 & 0.81 & 3.5 & 4.4 & 2.9 & 0.55 & 26.6 & 68.1 & 5.3 & $\mathrm{SiL}$ \\
\hline & $\mathrm{AP} 2 \mathrm{~g}$ & $12 \sim 22$ & 8.1 & 14.06 & 0.35 & 2.9 & 5.3 & 4.4 & 1.14 & 36.7 & 54.8 & 8.5 & $\mathrm{SiL}$ \\
\hline & $\mathrm{Clg}$ & $22 \sim 35$ & 8.0 & 14.06 & 0.63 & 1.9 & 5.6 & 2.7 & 1.2 & 19.3 & 60.6 & 20.1 & $\mathrm{SiL}$ \\
\hline
\end{tabular}

과 같은 사양토, 미사질양토, 또는 양토의 토성을 가지고 있 는 것으로 조사되었다 (NHAES. 2002).

간척지토양의 토양입자분포 특성을 살펴보면 새만금지역 의 광활통의 경우 지표면 $30 \mathrm{~cm}$ 이내에서는 미사함량이 $50 \%$ 이상 존재하며 다음 모래가 약 $40 \%$, 그리고 점토가 $10 \%$ 이하로 존재하고 있다(Park, 2008). 따라서 점토 크기 에 가까운 미사함량이 증가할수록 토양내 공극의 크기는 감 소하여 배수가 불량해진다. 그리고 토양에 가해지는 질소공 급원인 요소 전환에 영향을 미치는 토양 $\mathrm{pH}$ 는 염포통과 포 승통을 제외한 나머지 토양통 모두에서 7 이상 알카리토양 으로 조사되었다. 그리고 염류농도는 조사된 모든 토양통에 서 $4 \mathrm{dS} \mathrm{m}^{-1}$ 이상으로 작물체가 자라는데 부적합한 것으로 판단된다. 그리고 $\mathrm{A}$ 또는 $\mathrm{Ap}$ 층의 입도분포를 살펴보면 점토 함량은 광활통의 경우 8.5\%가 최대로 조사되었다 (Table 4).

한편 $\mathrm{KRCC}(2010)$ 가 영산강 간척지 III 지구 토양을 대상 으로 조사한 결과를 살펴보면 조사대상지 모두 토양 $\mathrm{pH}$ 는 7 이상이며 $\mathrm{EC}$ 는 작물이 자라기에 부적합한 $8 \mathrm{dS} \mathrm{m}^{-1}$ 이상으 로 조사되었다 (Table 6).
그리고 논토양으로 활용하고 있는 영산강 $\Pi-1$ 지구 토양 통에 속하는 여수통, 포리통, 그리고 금진통간척지 토양의 화학적특성을 살펴보면(Jung, 2008a,b; Lee, 2008a) 표토 의 $\mathrm{pH}$ 는 5.6 이하로 약산성에 속하며 유기물함량은 일반 관 행논보다 다소 높으나 인산함량은 일반 농경지 토양보다 매 우 낮은 최대 $42 \mathrm{mg} \mathrm{kg}^{-1}$ 이었다 (Table 6).

Ryu(2008) 발표한 바에 따르면 간척년대별 토양물리성 변화를 살펴보면 새만금지역의 광활, 염포, 그리고 문포통 심토의 용적밀도와 경도 그리고 포장수분함량은 간척년대 가 경과할수록 조립질인 광활, 염포, 그리고 문포통은 낮아 지는 경향이나 반면 세립질 토양인 포승통과 포두통은 증가 하였다 (Table 8). 영산강간척지 시험포장의 토양깊이별 토 양경도를 조사한 결과 한빛뜰(태안통) 감자재배 포장을 제 외한 모든 포장에서 깊이 $15 \mathrm{~cm}$ 이하부터 토양경도가 식물 뿌리 침투신장의 한계범위인 $2 \mathrm{~kg} \mathrm{~cm}^{-2}$ 를 초과하는 것으로 조사되었다 (Fig. 6).

Chung(2012)이 새만금 광활통과 영산강 태안통 토양에서 조사한 용적밀도, 토양경도, 그리고 포화수리전도 측정 결 
Table 6. Chemical and physical properties of a reclaimed tidal soils in Youngsan-river reclaimed tidal area (KRCC, 2010).

\begin{tabular}{|c|c|c|c|c|c|c|c|c|}
\hline \multirow{2}{*}{ Name of Field } & \multirow{2}{*}{$\mathrm{pH}$} & \multirow{2}{*}{$\mathrm{EC}$} & \multirow{2}{*}{$\mathrm{CEC}$} & \multirow{2}{*}{$\mathrm{OM}$} & \multirow{2}{*}{ Avail. $\mathrm{P}_{2} \mathrm{O}_{5}$} & \multicolumn{3}{|c|}{ Ex. } \\
\hline & & & & & & $\mathrm{K}$ & $\mathrm{Ca}$ & $\mathrm{Mg}$ \\
\hline & & $\mathrm{dS} \mathrm{m}^{-1}$ & $\mathrm{cmol}_{+} \mathrm{kg}^{-1}$ & $\%$ & $m g \mathrm{~kg}^{-1}$ & \multicolumn{3}{|c|}{------ $\mathrm{cmol}_{+} \mathrm{kg}^{-1}$} \\
\hline Hanbit & 7.6 & 8.3 & 13.18 & 1.74 & 15.5 & 1.25 & 4.28 & 6.48 \\
\hline Samho & 7.5 & 8.7 & 18.33 & 1.33 & 17.8 & 1.83 & 3.86 & 8.61 \\
\hline Jangsoo & 7.3 & 14.6 & 14.13 & 1.06 & 16.4 & 1.51 & 2.68 & 6.92 \\
\hline Maebong & 7.5 & 10.3 & 15.90 & 1.29 & 18.3 & 1.43 & 3.93 & 7.68 \\
\hline Others & 7.6 & 12.0 & 16.14 & 1.02 & 19.6 & 1.67 & 4.57 & 7.66 \\
\hline
\end{tabular}

Table 7. Chemical and physical properties of a reclaimed tidal soils in Youngsan-river reclaimed tidal area (KRCC, 2010).

\begin{tabular}{|c|c|c|c|c|c|c|c|c|}
\hline \multirow{2}{*}{ Soil series } & \multirow{2}{*}{$\mathrm{pH}$} & \multirow{2}{*}{$\mathrm{OM}$} & \multirow{2}{*}{$\mathrm{P}_{2} \mathrm{O}_{5}$} & \multirow{2}{*}{ CEC } & \multicolumn{4}{|c|}{ Ex.cation } \\
\hline & & & & & K & $\mathrm{Ca}$ & $\mathrm{Mg}$ & $\mathrm{Na}$ \\
\hline & $1: 5$ & $\mathrm{~g} \mathrm{~kg}^{-1}$ & $\mathrm{mg} \mathrm{kg}^{-1}$ & $\mathrm{cmol}_{\mathrm{c}} \mathrm{kg}^{-1}$ & \multicolumn{4}{|c|}{ - } \\
\hline Yeosu & 5.6 & 25.6 & 30 & 16.9 & 1.13 & 4.7 & 5.5 & 3.8 \\
\hline Pori & 5.5 & 26.6 & 42 & 17.5 & 1.25 & 4.6 & 5.2 & 4.1 \\
\hline Gumjin & 5.3 & 26.9 & 16 & 19.2 & 1.63 & 4.9 & 2.6 & 6.0 \\
\hline
\end{tabular}

Table 8. Changes in bulk density and soil hardness for soils series of Kwanghal, Yumpo, and Moonpo at Saemangum area during five years after completion of reclamation.

\begin{tabular}{|c|c|c|c|c|}
\hline \multirow{2}{*}{$\begin{array}{c}\text { Soil } \\
\text { series }\end{array}$} & \multicolumn{2}{|c|}{ Bulk density } & \multicolumn{2}{|c|}{ Soil hardness } \\
\hline & $1^{\text {st }} \mathrm{yr}$ & $5^{\text {th }} \mathrm{yr}$ & $1^{\text {st }} \mathrm{yr}$ & $5^{\text {th }} \mathrm{yr}$ \\
\hline & \multicolumn{2}{|c|}{ - $\mathrm{g} \mathrm{cm}^{-3}$} & \multicolumn{2}{|c|}{---------------- mm ---------------- } \\
\hline Kwanghal & 1.605 & 1.354 & 19.2 & 19.8 \\
\hline Yumpo & 1.586 & 1.548 & 18.5 & 23.6 \\
\hline Moonpo & 1.548 & 1.535 & 19.2 & 26.1 \\
\hline
\end{tabular}

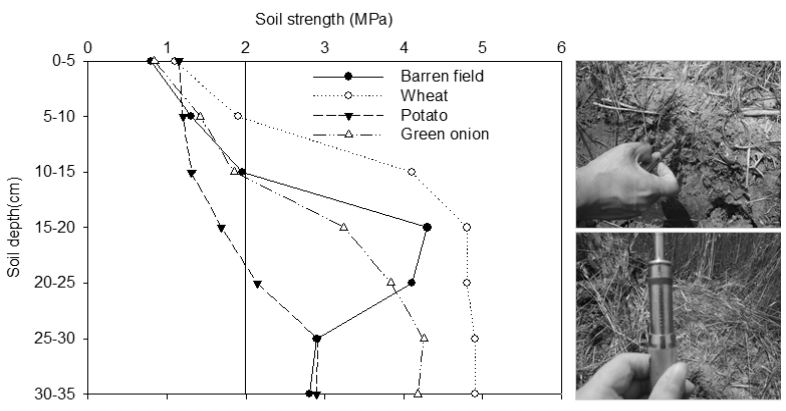

Fig. 6. Soil hardness measured at the reclaimed tidal area of Youngsan-river.

과를 살펴보면 일반 관행 농경지와 유사하게 경반층에 해당 하는 $25 \mathrm{~cm}$ 깊이에서 용적밀도가 최대치로 조사되었으며 이 지점에서 토양경도도 식물의 뿌리생육에 저해하는 18 $\mathrm{mm}$ 이상으로 조사되었다 (Gerard, 1982). 또한 포화수리전 도도도 $0-25 \mathrm{~cm}$ 깊이에서는 0.63 과 $0.51 \mathrm{~cm}$ 이나 $25-55 \mathrm{~cm}$ 깊이에서는 거의 투수가 되지않거나 0.11 로 급격히 감소하 는 경향을 보였다.

간척지토양은 토양의 단면조사에서도 알 수 있듯이 매우
높은 용적밀도를 가지고 있으며 일반적으로 투수성이 매우 불량하다고 알려져 있다. 용적밀도에 따른 간척지 토양의 투수성 변화를 조사한 결과 용적밀도별 초기 $\mathrm{K}$ 는 용적밀도 $1.30 \mathrm{~g} \mathrm{~cm}^{-3}$ 토주에서 0.68 공극수량 (pore volume) 용출 후 $0.10 \mathrm{~cm} \mathrm{hr}^{-1}$ 을 나타내었고, 용적밀도 $1.35 \mathrm{~g} \mathrm{~cm}^{-3}$ 토주에서 0.38 공극수량 용출 후 $0.06 \mathrm{~cm} \mathrm{hr}^{-1}$ 을 나타내었으며, 용적 밀도 $1.40 \mathrm{~g} \mathrm{~cm}^{-3}$ 토주에서는 0.29 공극수량 용출 후 0.04 $\mathrm{cm} \mathrm{hr}$ 를 나타내었다. 또한 용적밀도 $1.45 \mathrm{~g} \mathrm{~cm}^{-3}$ 에서는 0.24 공극수량 용출 후 $0.06 \mathrm{~cm} \mathrm{hr}^{-1}$ 를 나타내었고 용적밀 도 $1.50 \mathrm{~g} \mathrm{~cm}^{-3}$ 에서는 0.11 공극수량 용출 후 $0.02 \mathrm{~cm} \mathrm{hr}^{-1}$ 을 나타내었다. 그러나 시간이 경과함에 따라 투수성은 크 게 저하되어 용적밀도에 관계없이 투수가 되지 않아 결국 $\mathrm{K}$ 값은 0을 나타내는 특성을 보였다 (Chung, 2012). 이는 치 환성 $\mathrm{Na}^{+}$함량이 높은 간척지 토양에 전해질 농도가 낮은 일반 용수를 담수하면 토양의 점토 입자가 분산되고 분산된 점토는 공극수와 함께 중력에 의해 하향 이동하다가 미세한 공극의 막힘이 발생하여 $\mathrm{K}$ 가 감소되고 결국 투수가 정지되 는 것으로 판단된다 (Dawidowski and Koolen, 1987).

간척지토양은 $\mathrm{NaCl}$ 의 영향으로 토성에 비하여 액성한계 
Table 9. Soil physical properties and saturate hydraulic conductivity of Gwanghal series and Taean series.

\begin{tabular}{|c|c|c|c|c|}
\hline Soil depth & Bulk density & Soil hardness & $\mathrm{K}_{\mathrm{sat}}$ & Remarks \\
\hline $\mathrm{cm}$ & $\mathrm{g} \mathrm{cm}^{-3}$ & $\mathrm{~mm}$ & $\mathrm{~cm} \mathrm{hr^{-1 }}$ & \\
\hline $0-25$ & 1.34 & 13.8 & $0.63(0.31-0.72)^{*}$ & \\
\hline $25-55$ & 1.43 & 21.8 & $0.00(0.08-0.14)^{*}$ & \\
\hline $55-95$ & 1.37 & 19.4 & 0.37 & \\
\hline $95-$ & 1.46 & 17.4 & 0.46 & \\
\hline
\end{tabular}

( ) indicates the value measured at the Youngsan-river

Table 10. Soil mechanical properties of Kwanghal series.

\begin{tabular}{|c|c|c|c|c|c|c|c|c|}
\hline \multirow{2}{*}{\multicolumn{2}{|c|}{ Category }} & \multirow{2}{*}{ Depth } & \multicolumn{5}{|c|}{ Period of reclamation (yr) } & \multirow{2}{*}{$\begin{array}{c}\mathrm{r} \\
(\mathrm{n}=13)\end{array}$} \\
\hline & & & 5 & 21 & 33 & 52 & 65 & \\
\hline \multirow{2}{*}{\multicolumn{2}{|c|}{ Cole }} & Soil surface & 0.026 & 0.035 & 0.047 & 0.052 & 0.055 & 0.966 \\
\hline & & Subsurface & 0.025 & 0.032 & 0.041 & 0.047 & 0.050 & 0.974 \\
\hline \multirow{6}{*}{$\begin{array}{c}\text { Atterberg } \\
\text { limits } \\
(\%)\end{array}$} & Liquid & Soil surface & 36.7 & 35.4 & 33.2 & 28.8 & 25.5 & -0.984 \\
\hline & limit & Subsurface & 37.4 & 35.9 & 33.5 & 29.3 & 26.1 & -0.988 \\
\hline & Plastic limit & Soil surface & 23.5 & 22.6 & 20.2 & 17.9 & 16.3 & -0.990 \\
\hline & Hastic intilt & Subsurface & 23.5 & 23.3 & 21.0 & 18.4 & 16.8 & -0.982 \\
\hline & Plastic & Soil surface & 13.2 & 12.8 & 13.0 & 10.9 & 9.2 & -0.917 \\
\hline & index & Subsurface & 13.9 & 12.6 & 12.5 & 10.9 & 9.3 & -0.977 \\
\hline
\end{tabular}

와 소성지수가 높다. Cole값은 점토함량, 유기물함량, Atterberg limits와는 정의 관계이나 수분함량과는 부의 상관성을 가 지고 있다. Kim (2008) 발표한 바에 따르면 새만금 광활통 토양의 액성한계와 소성한계, 그리고 소성지수는 액성한계 가 표토보다 심토에서 약간 높으며 부의 상관성을 나타내는 것은 심토의 점토 함량이 높은 것이 원인으로 추정된다. 한 편 광활통은 33 년차부터 경반층이 생성되었다 (Table 10).

\section{Summary}

간척지토양은 일반적으로 매우 높은 염농도를 가지고 있 으며 염고농도의 염 특히, 높은 $\mathrm{Na}^{+}$농도는 점토의 분산을 일으키고 토양의 공극을 감소시켜 토양의 공기와 수분의 유 통을 악화시키고 고농도의 염은 생리적가뭄(physiological drought)의 한 가지 형태인 낮은 수분퍼텐셜을 발생시켜서 수분과 양분의 흡수를 어렵게 한다. 따라서 간척지를 효율 적으로 활용하기 위해서는 간척지 토양에 대한 제염이 선행 되어야 한다. 이러한 제염 효과를 증진시키기 위해서는 상 기에서 살펴본 바와 같이 물리성 개선을 통하여 토양의 화 학성을 개선시켜야 한다. 본 조사를 기준으로한 간척지토양 개선은 물리성 중 물질의 이동을 용이하게 하는 심층토 내 토양압밀층 개선이 우선되어야 할 것으로 판단한다. 그리고 높은 지하수위에 의한 모세관상승에 동반한 재염화를 방지 하기 위한 토양관리방안이 필요하다. 따라서 최종적으로 간 척지의 효과적 재염 (Resalization)방지와 제염(Desalinazation)
방안에 대한 토질역학적 측면에서 연구가 추진되어야 한다.

\section{Acknowledgement}

This work was carried out with the support of "Cooperative Research Program for Agriculture Science \& Technology Development (Project No. PJ008516)” Rural Development Administration, Republic of Korea.

\section{References}

Chung, D.Y. 2012. Unpublished data

Dawidowski1, J.B. and A.J. Koolen. 1987. Changes of soil water suction, conductivity and dry strength during deformation of wet undisturbed samples. Soil Till. Res. 9:169-180.

Gerard, C.J. P. Sexton, and G. Shaw. 1982. Physical Factors Influencing Soil Strength and Root Growth. Agron. J. 74:875-879

Jung, J.H. 2008. Soil series of a reclaimed tidal soil-Bogchung series.

Jung, J.H. 2008a. Soil series of a reclaimed tidal soil-Yeosu series. http://blog.daum.net/viny9364/7826665

Jung, J.H. 2008b. Soil series of a reclaimed tidal soil-Pori series. http://blog. daum.net/viny9364/7826804

Kim, T.G. 2008. Changes of physical and chemical properties of a reclaimed tidal soils with reclamation ages. 
http://blog.daum.net/viny9364/7826417

KRCC. 2002. Status of Reclamation Project Progress 2002. KRCC

KRCC. 2007. Status of Reclamation Project Progress 2007. KRCC

KRCC. 2010. Report of soil characteristics for Youngsan-river reclaimed tidal area. KRCC

Lee, D.G. 2008a. Soil series of a reclaimed tidal soil-Gumjin series. http://blog. daum.net/viny9364/7826414

Lee, G.H. 2008. Soil characteristics of reclaimed tidal area at the Youngsan- river. http://blog.daum.net/viny9364/7826392

MAF. 2009. Food, Agricultural, Forestry and Fisheries
Statistical Yearbook

NHAES. 2002. Agriculture in a reclaimed tidal soils in Korea. RDA.

Park, K. H. 2008. Characteristics of soils for a reclaimed tidal soils at Gyehwa area-Chemical and physical properties.

Ryu, J.H. 2008. Classification of reclaimed tidal soils. http://blog.daum.net/ viny9364/7826419. RDA.

Ryu, J.H. 2009. Problems in a newly reclaimed tidal soil. http://blog.daum.net/ viny9364/7826774

Ryu, J.H. 2010. Ph. D. Thesis. Chungnam National University. Yang, C.H. 2008. Changes in groundwater table in a reclaimed tidal soils at Saemangum. 